\title{
Pelatihan Teknologi Budidaya Udang Sistem Polikultur pada Kelompok Tani Pembudidaya Udang Di Desa Tamarupa Kecamatan Mandalle Kabupaten Pangkep, Provinsi Sulawesi Selatan
}

\author{
Harlina Harlina, Muhammad Saenong, Andi Hamdillah \\ Jurusan Budidaya Perairan, Fakultas Perikanan dan Ilmu Kelautan, Universitas Muslim \\ Indonesia, Makassar, Jl urip Sumoharjo Km 05 Makassar
}

Email: harlina.harlina@umi.ac.id

\begin{abstract}
Abstrak - Salah satu desa di Kabupaten Pangkajene Kepulauan adalah Desa Tamarupa Kecamatan. Mandalle merupakan wilayah pesisir yang sebagian besar penduduknya menggantungkan hidupnya sebagai petani tambak. Di desa ini terdapat kelompok tani "Sipakaenre II" yang merupakan kelompok pembudidaya udang. Masalah utama yang dihadapi oleh kelompok pembudidaya udang ini adalah rendahnya produksi udang yang dihasilkan karena teknologi yang digunakan masih tradisional dengan mengandalkan pakan alami dengan metode monokultur. Produksi udang dapat ditingkatkan dengan meningkatkan teknologi budidaya. Untuk itu tujuan program kemitraan masyarakat (PKM) ini adalah memberi pemahaman dan penguasaan kepada kelompok pembudidaya udang tentang cara budidaya udang yang baik dengan melalui kegiatan pelatihan tentang teknik budidaya udang secara polikultur berbasis Cara Budidaya Ikan dengan Baik (CBIB). Metode yang digunakan adalah metode partisipatif yang melibatkan secara langsung anggota kelompok dalam diskusi dan praktek. Setelah kegiatan ini dilakukan pengetahuan dan pemahaman kelompok pembudidaya meningkat dan mampu menerapkan teknologi budidaya udang dengan sistem Polikultur berbasis CBIB.
\end{abstract}

Kata Kunci: Budidaya udang, ikan bandeng, polikultur, CBIB, Kelurahan Tamarupa

\begin{abstract}
One of the villages in Pangkajene and Islands District is Tamarupa Village, Mandalle District, which is a coastal area. Most of the population are fish farmers. In this village, there is a shrimp farmer group "Sipakaenre II". The main problem faced by farmer group is the low production of shrimp because the technology used is still traditional, relying on natural food and using the monoculture method. Shrimp production can be increased by improving aquaculture technology. For this reason, the purpose of this community partnership program (CPP) was to provide a better understanding and skill to shrimp farmer groups about how to cultivate good shrimp through training activities of polyculture shrimp farming techniques based on Best Aquaculture Practice (BAP). The approach method used to achieve the objectives of the community partnership program was a participatory method. After this activity, there was an increase in the knowledge and skills of farmer group partners about shrimp aquaculture technology with BAP-based on polyculture systems.
\end{abstract}

Keywords: Shrimp farming, milkfish, polyculture, CBIB, Tamarupa Village

\section{PENDAHULUAN \\ Analisis Situasi}

Kabupaten Pangkep (Pangkajenne

Kepulauan ), memiliki wilayah yang cukup luas yaitu sekitar $12.362,73 \mathrm{~km}^{2}$ terdiri dari daratan dan lautan dengan luas masing-masing $898,29 \mathrm{~km}^{2}$ berupa daratan dan $11.464,44 \mathrm{~km}^{2}$ berupa laut. Kabupaten Pangkep memiliki panjang garis pantai $45 \mathrm{~km}$.

Kegiatan budidaya udang di Kabupaten Pangkep menunjukkan perkembangan yang cukup pesat, yang ditandai dengan bertambah luasnya pengalihan fungsi lahan sawah menjadi lahan tambak yang digunakan untuk membudidayakan udang maupun ikan bandeng di wilayah ini. Kedua komoditas ini menjadi komoditi andalan Kabupaten
Pangkep sehingga dikenal sebagai pemasok utama dalam memenuhi kebutuhan sehari-hari masyarakat yang berdomisili di berbagai daerah yang ada di Makassar dan Sulawesi Selatan pada umumnya [1].

Lahan tambak yang digunakan oleh petani pembudidaya udang dan ikan bandeng mencapai 10.000 hektar. Produksi yang dihasilkan yaitu udang 12.546 ton, udang windu dan udang Vannamei masing-masing 1.181 ton dan 1.329 ton pada tahun 2016 yang tersebar di semua kecamatan di Kabupaten Pangkep [2]. Produksi udang masih dapat ditingkatkan dengan memperbaiki teknologi budidaya serta menerapkan sistem polikultur berbasis CBIB. 


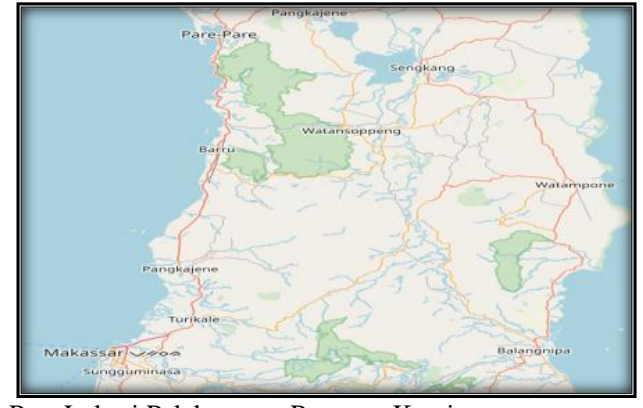

Gambar 1 Peta Lokasi Pelaksanaan Program Kemitraan Masyarakat

Kelurahan Tamarupa, Kec. Mandalle, Kabupaten Pangkajene Kepulauan merupakan wilayah pesisir yang sebagian besar penduduknya menggantungkan hidupnya sebagai petani tambak. Di desa ini terdapat kelompok tani "Sipakaenre II" yang menjadi mitra pada kegiatan pengabdian kepada kelompok pembudidaya udang ini.

Permasalahan yang dialami oleh pembudidaya udang "Sipakaenre II" Kelurahan Tamarupa Kecamatan Mandalle (mitra) dalam mengelola usahanya adalah rendahnya produksi dalam budidaya udang karena dalam kegiatan budidayanya masih tradisional dengan metode monokultur. Terbatasnya pengetahuan masyarakat petani tambak dalam teknik budidaya udang yang menyebabkan sebagian besar petani mengelola usahanya dengan metode tradisional sebagaimana yang diperoleh secara turun temurun. Kegiatan budidaya secara berkelompok belum sepenuhnya diterapkan karena pemahaman manajemen usaha secara berkelompok masih sangat rendah.

Kegiatan program kemitraan masyarakat bertujuan untuk membantu meningkatkan produksi udang dengan menerapkan teknik budidaya udang secara polikultur berbasis CBIB. Budidaya sistem polikultur adalah pemanfaatan areal budidaya dengan memelihara lebih satu jenis organisme dalam satu wadah terkontrol. Sistem ini meningkatkan efisiensi penggunaan areal budidaya dan menyebabkan meningkatnya pendapatan pembudidaya serta diperoleh hasil berkesinambungan [3]. Syarat organisme yang dipolikultur harus tidak saling mengganggu dan bersinergi.

\section{Permasalahan Mitra}

Kelompok tani yang berdomisili di Kelurahan Tamarupa pada umumnya membudidayakan udang sepanjang tahun. Budidaya udang berlangsung selama 4 bulan yaitu mulai pada bulan April hingga Agustus setiap tahun. Rendahnya produksi udang disebabkan oleh teknologi budidaya yang digunakan masih konvensional dengan sistem monokultur. Dalam kegiatan budidayanya dilakukan dengan teknologi konvensional yakni hanya mengandalkan makanan alami yang hidup di dalam perairan tanpa pemberian makanan tambahan. Keberadaan makanan alami sangat menentukan laju pertumbuhan udang, terutama pada stadia post larva). Akan tetapi jumlah dan ukurannya tidak sesuai dengan kebutuhan ikan. Berdasarkan uraian di atas maka permasalahan prioritas yang dihadapi kelompok masyarakat petani Kelurahan Tamarupa adalah sebagai berikut :

1. Rendahnya produksi dalam budidaya udang karena dalam kegiatan budidayanya masih bersifat tradisional dengan metode monokultur dan tidak berbasis CBIB.

2. Terbatasnya pengetahuan masyarakat petani tambak dalam teknik budidaya udang yang menyebabkan sebagian besar petani mengelola usahanya dengan sistem tradisional sebagaimana yang diperoleh secara turun temurun.

3. Kegiatan budidaya secara berkelompok belum sepenuhnya diterapkan karena pemahaman manajemen usaha masih sangat yang rendah.

\section{Solusi Permasalahan yang ditawarkan}

Berdasarkan permasalahan yang dihadapi petani pembudidaya udang, maka solusi mengatasi permasalahan tersebut adalah sebagai berikut:

1. Peningkatan produksi budidaya udang dengan introduksi teknologi budidaya udang dengan system polikultur dengan bandeng dengan system CBIB, sehingga selain dapat meningkatkan produksi dengan memperoleh hasil dari kedua komoditas dalam satu siklus usaha budidaya.

2. Melakukan Penyuluhan/ pelatihan terhadap kelompok petani tambak untuk memberi pengetahuan, pemahaman dan keterampilan teknik budidaya udang secara polikultur berbasis CBIB

3. Melakukan pendampingan tentang pengaplikasian teknik budidaya secara berkelompok dalam penerapan metode budidaya udang secara polikultur dengan sistem CBIB

\section{METODE PELAKSANAAN}

\section{Waktu dan Tempat Pelaksanaan Kegiatan,}

Kegiatan program kemitraan masyarakat dilakukan pada bulan Agustus sampai bulan November 2020 di Desa Tamarupa Kecamatan Mandalle Kabupaten Pangkep.

\section{Metode Yang Digunakan}

Metode yang digunakan dalam pelaksanaan PKM ini adalah metode partisipatif dengan melibatkan secara langsung anggota kelompok dalam diskusi dan praktek, melalui 
kegiatan: 1) Pelatihan tentang teknologi Budidaya Udang secara Polikultur dengan ikan bandeng dengan sistem CBIB ;2). Pelatihan/Pendampingan penerapan teknologi budidaya polikultur berbasis CBIB.

Tahapan pelaksanaan kegiatan meliputi persiapan, pelaksanaan kegiatan, memonitoring dan mengevaluasi kegiatan. Adapun rincian pelaksanaan kegiatan yang dilakukan dibagi ke dalam tiga tahapan yaitu:

1. Tahap persiapan, pada tahap ini dilakukan sosialisasi dengan mengunjungi kelompok pembudidaya udang "sipakaenre II" dan kepala desa tentang rencana pelaksanaan kegiatan Program Kemitraan Masyarakat di Kelurahan Tamarupa Kecamatan Mandalle Kabupaten Pangkajenne Kepulauan.

2. Tahap pelaksanaan kegiatan pelatihan, pada tahap ini dilakukan pelatihan teknik budidaya udang dengan sistem polikultur berbasis sistem CBIB, pendampingan penerapan teknologi budidaya udang dengan metode polikultur berbasis sistem CBIB.

3. Tahap mengevaluasi dan memonitoring kegiatan: setelah seluruh tahapan pelaksanaan kegiatan, dilakukan evaluasi terhadap peserta sejauh mana pemahaman terhadap materi pelatihan yang telah diberikan.

\section{HASIL DAN PEMBAHASAN Tahapan Persiapan}

Kegiatan PKM ini dilakukan dalam tiga tahapan kegiatan yaitu: Tahap pertama adalah melakukan kegiatan sosialisasi (Gambar 1), pada kegiatan ini ditetapkan 1 (satu) anggota kelompok sebagai pendamping di lapangan selama berlangsungnya pelaksanaan kegiatan. Menentukan waktu pelaksanaan kegiatan PKM dan besarnya jumlah peserta anggota kelompok pembudidaya udang berdasarkan kesepakatan yaitu jumlah peserta dari anggota kelompok disepakati sekitar 10-15 orang.

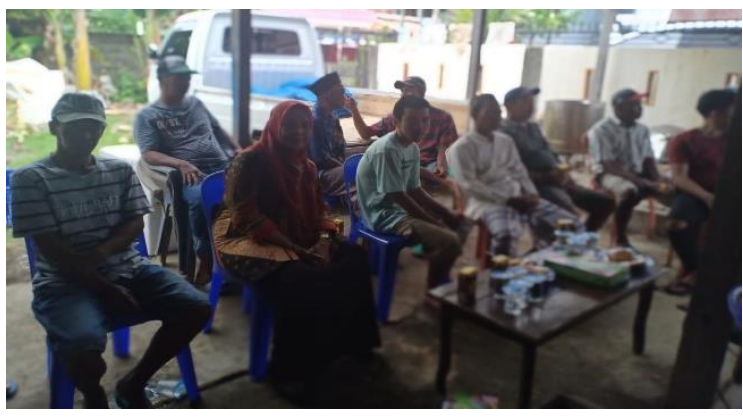

Gambar 2. Kegiatan sosialisasi pelaksanaan kegiatan PKM

\section{Tahap Pelaksanaan}

Tahap pelaksanaan dilakukan dalam bentuk kegiatan pelatihan/pendampingan teknik Budidaya udang dengan sistem polikultur dengan ikan bandeng, kepada kelompok pembudidaya udang "Sipakaenre II". Tim pelaksana bertindak sebagai penyuluh dan pendamping dalam melakukan kegiatan budidaya udang secara polikultur yang dilakukan bersama dengan mitra. Pelatihan untuk memberi pemahaman tentang keuntungan dan teknik penerapan teknologi secara polikultur.

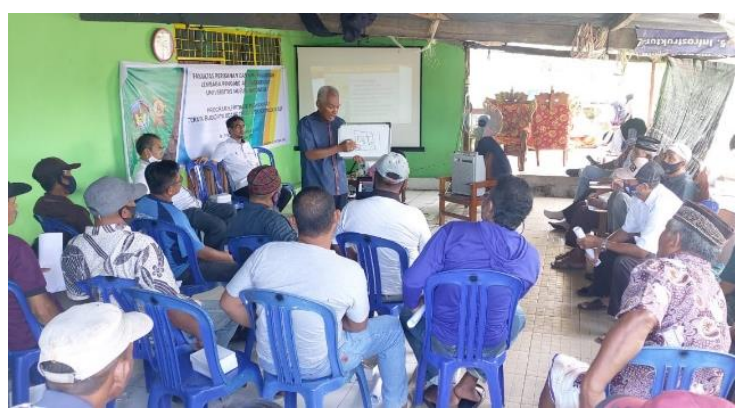

Gambar 3. Kegiatan Pelatihan teknik Budidaya Udang dengan Teknologi Polikultur

Materi pelatihan tentang tambak dan upaya pengelolaannya. Tambak adalah lahan buatan yang merupakan percampuran air yang bersumber dari daratan yang sifatnya tawar dan air yang berasal dari laut yang diperuntukkan untuk membudidayakan organisme [4]. Areal pertambakan adalah merupakan perairan air payau terletak di daerah pesisir dipergunakan sebagai wadah untuk memelihara ikan. Teknologi budidaya udang dimulai dari persiapan lahan hingga panen. Kegiatan budidaya diawali dengan melakukan perbaikan tanah dasar tambak, dilakukan pencucian air tambak untuk membuang endapan lumpur yang berwarna hitam dan berbau busuk dengan cara pemompaan air dan pencucian sedimen yang ada di dasar tambak. Untuk menaikkan $\mathrm{pH}$ tanah dilakukan pengeringan dan pengapuran. Menurut Hazelton dan Murphy [5], pemberian kapur pada tambak dapat menetralisir kadar $\mathrm{pH}$ untuk waktu yang cukup lama. Sedangkan pengeringan, selain menetralisir keasaman tanah, pengeringan juga berfungsi memberantas hama dan penyakit, mempercepat proses pembongkaran sisa kotoran menjadi mineral, menghilangkan senyawa beracun dan memberikan ruang $\mathrm{O}_{2}$ pada tanah [6]. Kegiatan selanjutnya adalah pemupukan sesuai dengan SOP cara budidaya ikan yang baik. Pemupukan berfungsi menumbuhkan pakan alami [7]. Setelah persiapan lahan selesai dilanjutkan dengan pemeliharan. Selama pemeliharaan diperlukan mengontrol kualitas air agar senantiasa berada pada kondisi yang layak untuk kehidupan organisme [8]. 


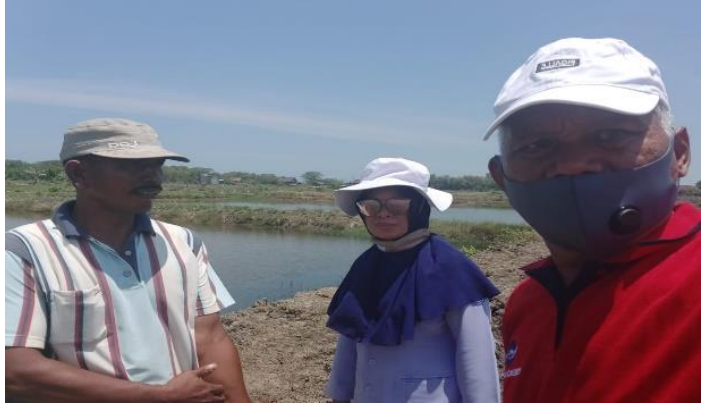

Gambar 4. Lokasi Pelaksanaan Program Kemitraan Masyarakat Desa Tamarupa Kec. Mandalle Kab. Pangkep

\section{Tahap Evaluasi}

Evaluasi kegiatan dilakukan setelah kegiatan penyuluhan dengan melakukan diskusi dan Tanya jawab untuk mengetahui apakah ada peningkatan pemahaman/pengetahuan anggota kelompok pembudidaya udang dalam melakukan praktek penerapan budidaya secara polikultur dengan benar. Berdasarkan hasil diskusi dan tanggapan balik kelompok mitra, serta pengamatan di lapangan dapat diperoleh informasi bahwa teknologi budidaya yang diperkenalkan kepada kelompok pembudidaya udang dipahami, dimengerti dapat diterapkan sesuai dengan harapan. Mitra optimis dapat melakukan kegiatan budidaya polikultur sehingga dalam waktu yang bersamaan dapat memperoleh dua komoditas sekaligus yaitu udang dan ikan bandeng sehingga pendapatan meningkat dan lebih mampu menopang kehidupan mereka agar bisa lebih sejahtera pada masa mendatang.

\section{KESIMPULAN}

Adanya pelaksanaan PKM pada kelompok pembudidaya udang menghasilkan kelompok pembudidaya udang yang memiliki pengetahuan tentang penerapan teknologi budidaya udang secara polikultur dengan ikan bandeng sehingga usaha budidaya akan memberi hasil yang lebih maksimal karena memperoleh dua hasil dalam waktu yang bersamaan sehingga hasil produksi meningkat. Anggota kelompok pembudidaya udang termotivasi melakukan kegiatan produksi udang dan bandeng secara berkelompok dengan sistem polikultur. Kelompok pembudidaya udang lebih optimis dan bertekad untuk dapat meningkatkan produksi ikan dengan mengaplikasikan teknologi polikultur dengan sistem CBIB dengan harapan dapat meningkatkan kesejahteraan masyarakat pembudidaya udang.

\section{UCAPAN TERIMA KASIH}

Kami mengucapkan terima kasih yang sebesar-besarnya untuk bapak Rektor Universitas Muslim Indonesia yang memberi bantuan pendanaan melalui Lembaga Pengabdian Kepada Masyarakat (LPkM) UMI untuk pelaksanaan kegiatan penelitian ini melalui Hibah Skim PKM Lektor Internal UMI. Terima kasih juga ditujukan kepada Kepala DesaTamangapa, Kecamatan Ma'rang, Kabupaten Pangkep, Provinsi Sulawesi Selatan beserta seluruh jajarannya atas pemberian izin dan juga bantuan dalam persiapan dan pelaksanaan kegiatan program kemitraan masyarakat ini.

\section{DAFTAR PUSTAKA}

[1]. Harlina, H., Hadijah, Kamaruddin dan Ernaningsih. 2019. Inovasi Teknologi Pembuatan Pakan Udang dengan Penambahan Tepung Kopasanda (Chromolaena odorata L.) di Desa Tamangapa Kecamatan Ma'rang Kab. Pangkep

[2]. BPS Kab Pangkajene Kepulauan 2017. Kec. Mandalle dalam Angka Tahun 2017. Badan Pusat statistic Kab Pangkep. ISSN 0215-7047

[3]. Direktorat Kredit Biro Pengembangan UMKM. 2008. Budidaya Rumput Laut Polikultur Bandeng. Pola Pembiayaan Usaha Kecil. Bank Indonesia.

[4]. Jamaluddin, A. N., Ratniarsih, I., Widjajanti, W.W. 2013. Perencanaan dan Perancangan Pusat Pengembangan Budidaya Ikan Bandeng Tambak di Sidoarjo.

[5]. Hazelton, P. dan Murphy, B. 2009. Interpreting Soil Test Results: What do All the Numbers Mean? CSIRO Publishing, Collingwood, $152 \mathrm{pp}$.

[6]. Haliman, R. Dan D. Adijaya. 2005. Udang Vanname. Penebar Swadaya. Jakarta.

[7]. Gunarto, 2008. Beberapa aspek penting dalam budidaya udang vannamei (Litopenaeus vannamei) dengan sistem pemupukan susulan di tambak (tradisional plus). Media Akuakultur, 3(1): 15-24.

[8]. Wahono, B., B., D. Prihatmoko, L. Mudiarti. 2019. PKM Kelompok Petambak Udang Dalam Upaya Memantau Dan Menjaga Kualitas Tambak Di Kecamatan Mlonggo Kabupaten Jepara. Jipemas, 2 (1) 